\title{
A decrease in brown adipose tissue activity is associated with weight gain during chemotherapy in early breast cancer patients
}

Angeline Ginzac ${ }^{1,2,3^{*}}$ (D), Bertrand Barres ${ }^{4}$, Marion Chanchou ${ }^{4}$, Emilie Gadéa ${ }^{5}$, loana Molnar ${ }^{1,2,3}$, Charles Merlin ${ }^{4}$, Bruno Coudert ${ }^{6}$, Emilie Thivat ${ }^{1,2,3}$ and Xavier Durando ${ }^{1,2}$

\begin{abstract}
Background: A decrease in thermogenesis is suspected to be implicated in the energy expenditure reduction during breast cancer treatment. This study aimed to investigate the impact of chemotherapy on the metabolic activity of brown adipose tissue (BAT) and the link with weight variation.

Methods: This was an ancillary analysis of a multicentre trial involving 109 HER2+ breast cancer patients treated with neoadjuvant chemotherapy. A centralised review of ${ }^{18} \mathrm{~F}-\mathrm{FDG}$ uptake intensity (SUV $\max$ ) in specific BAT regions (cervical and supraclavicular) was conducted on two PET-CT scans for each patient (before and after the first course of chemotherapy).

Results: Overall, after one course of chemotherapy a significant decrease of $4.4 \%$ in ${ }^{18}$ F-FDG-uptake intensity was observed. It was not correlated to initial BMl, age or season. During chemotherapy, $10.1 \%(n=11)$ of the patients lost weight $(-7.7 \mathrm{~kg} \pm 3.8 \mathrm{~kg}$; ie, $-9.4 \% \pm 3.7 \%)$ and $29.4 \%(n=32)$ gained weight $(+5.1 \mathrm{~kg} \pm 1.7 \mathrm{~kg} ; \mathrm{ie},+8.5 \% \pm$ 2.6\%). Among these subgroups, only the patients who had gained weight underwent a significant decrease $(13.42 \%)$ in ${ }^{18} \mathrm{~F}-\mathrm{FDG}$ uptake intensity $(p=0.042)$.

Conclusion: This study is the first to highlight in a large cohort of patients the negative impact of chemotherapy on brown adipose tissue activity. Weight gain during chemotherapy could thus potentially be explained in part by a decrease in brown adipose tissue activity.
\end{abstract}

Keywords: Brown adipose tissue, Energy metabolism, Weight gain, Breast cancer

\section{Background}

Excess body weight is a recognized breast cancer risk factor and also a factor of poor prognosis at diagnosis (high recurrence and mortality rates) [1, 2]. Weight gain during breast cancer treatment, in particular during chemotherapy, is also linked to poor prognosis [3-7]. The mechanisms that explain weight change are not

\footnotetext{
* Correspondence: Angeline.ginzac@clermont.unicancer.fr

'Centre Jean PERRIN, INSERM, U1240 Imagerie Moléculaire et Stratégies Théranostiques, Université Clermont Auvergne, F-63011 Clermont-Ferrand, France

${ }^{2}$ Délégation Recherche Clinique \& Innovation, Centre Jean PERRIN, Centre de Lutte contre le Cancer, 58 rue Montalembert, F-63011 Clermont-Ferrand, France

Full list of author information is available at the end of the article
}

clearly understood [8]. Weight change results from an energy imbalance, i.e. food intake versus energy expenditure $[9,10]$. Nausea, vomiting or even loss of appetite for example can disturb food intake, thus affecting energy intake [9]. Energy expenditure is explored by way of resting energy expenditure (REE), physical activity and adaptive thermogenesis. BAT (brown adipose tissue) contains numerous mitochondria harbouring a particular protein, the uncoupling protein-1 (UCP-1) which confers a specific function to this tissue: heat production [11]. Thus, BAT contributes to thermogenesis [12].

BAT has received considerable attention since it is considered as a potential target to limit obesity and metabolic syndromes. Its contribution to human energy

(c) The Author(s). 2020 Open Access This article is distributed under the terms of the Creative Commons Attribution 4.0 International License (http://creativecommons.org/licenses/by/4.0/), which permits unrestricted use, distribution, and reproduction in any medium, provided you give appropriate credit to the original author(s) and the source, provide a link to the Creative Commons license, and indicate if changes were made. The Creative Commons Public Domain Dedication waiver (http://creativecommons.org/publicdomain/zero/1.0/) applies to the data made available in this article, unless otherwise stated. 
metabolism needs further investigation. BAT is known to affect energy metabolism in murine models. Indeed, Lowell et al. showed that the ablation of BAT leads to obesity [13]. Feldmann et al. drew the same conclusion, showing that UCP1 ablation led to obesity in mice [14]. Studies using fluorine-18 fluorodeoxyglucose $\left({ }^{18} \mathrm{~F}\right.$-FDG) positron emission tomography (PET) scans have evidenced the presence of BAT in adults [15-18]. ${ }^{18}$ F-FDG is currently used in oncology to mark tumours but it is not specific and has been found in high glucose metabolism organs such as BAT [19-21]. BAT is localized in the cervical and supraclavicular regions [22, 23]. Only two studies, including ours, have focused on BAT activity during breast cancer chemotherapy [24, 25]. Rousseau et al. studied BAT uptake variations among 33 early breast cancer patients who had 5 FDG PET scans during chemotherapy. The authors found that BAT uptake was highly variable across patients, independently from outdoor temperatures. They also showed that patients treated with taxane-based chemotherapy were those with the more significant changes on PET-CT scan compared to those treated with anthracycline-based chemotherapy [25]. Our team hypothesised that chemotherapy decreases BAT activity and leads to weight gain. Indeed, our previous pilot study on a small sample of patients (26 early breast cancer patients included in the AVATAXHER trial in Jean PERRIN Comprehensive Cancer Centre) showed a decrease in ${ }^{18}$ F-FDG uptake in BAT regions after one course of chemotherapy [24]. More specifically, our team found that patients gaining weight (>5\% of initial weight) during chemotherapy underwent a significant decrease in BAT activity compared to patients who remained stable or lost weight [24]. One limitation of these two studies is that they were conducted on a few patients only. Data on larger cohorts is needed. The primary objective of the present study was to assess the impact of one course of chemotherapy on BAT activity in 109 early breast cancer patients. The secondary objectives were to assess the relationship between BAT activity variations and weight variations at the end of chemotherapy, and to study the factors influencing BAT activity.

\section{Methods}

\section{Study population and clinical data}

The present study was an ancillary analysis to a national prospective multicentre trial, the AVATAXHER trial (NCT01142778), approved by the local ethics committee and the competent authority. A non-opposition letter has been delivered to the patients in order to inform them about the research. Among the 128 patients potentially eligible for our ancillary study, 109 were included in the assessment (there were 2 oppositions to the use of medical data and 17 had missing or uninterpretable PET/CT).

All patients had been diagnosed with HER2-positive early breast cancer and received neoadjuvant chemotherapy ( 2 cycles of docetaxel + trastuzumab, then patients with a decrease in SUV $(<70 \%)$ were randomized in a 2 : 1 ratio to receive trastuzumab + docetaxel \pm bevacizumab for cycles 3 to 6 whereas patients with a change in SUV $\geq 70 \%$ received trastuzumab + docetaxel). Patients were treated with 6 courses of neoadjuvant chemotherapy followed by 12 injections of trastuzumab, one of which was before surgery.

\section{PET-CT scan review}

A specific procedure for the conduct of PET-CT scans is in force in all facilities concerned. Patients were instructed to fast at least $6 \mathrm{~h}$ before ${ }^{18} \mathrm{~F}$-FDG injection and to avoid muscular effort the day before. After ${ }^{18} \mathrm{~F}$ FDG administration, patients were asked to keep still and warm to avoid brown adipose tissue fixation. The temperature in the examination room was the same in each centre.

Early response to treatment was evaluated by fluorine18 fluorodeoxyglucose $\left({ }^{18} \mathrm{~F}\right.$-FDG) $\mathrm{PET} / \mathrm{CT}$ scan before (PET 1) and after one course of chemotherapy (PET 2) (Fig. 1). All patients received a short corticosteroid therapy (24 to $48 \mathrm{~h}$ ), as part as premedication for docetaxel, which must not influenced BAT activity. Indeed, PET1 and PET2 have been realised before any steroid therapy [26] (see Additional file 1). PET-CT images were visualised on Oasis software V1.8.3 (Segami). All the ${ }^{18}$ F-FDG $\mathrm{PET} / \mathrm{CT}$ scans were centralised and reviewed twice, by two physicians from our institution, experienced in nuclear medicine. The metabolic activity of BAT was measured by the maximum standard uptake value (SUVmax) [27]. A spherical region of interest (ROI) of $10 \mathrm{~mm}$ in diameter was used to quantify ${ }^{18} \mathrm{~F}$-FDG uptake (maximum standardized uptake value $\left.\left(\mathrm{SUV}_{\max }\right)\right)$ in the BAT regions, i.e. the cervical and supraclavicular regions [28], and in control tissues. ROIs were placed manually on each image in different specific anatomical regions: the contralateral breast (white fat), the deltoid (muscle) and the liver as controls, and the supraclavicular region (right and left), and in the upper and lower cervical regions (right and left).

\section{Statistical analysis}

$\mathrm{R}$ software (version 3.5, R-Project, GNU GPL) was used to perform the statistical analyses. Patient characteristics were described using mean and standard deviation or median and range in case of a non-Gaussian distribution for quantitative parameters. For the hypothesis tests, the significance threshold was fixed at 0.05 . For comparisons of before/after measures, we used Wilcoxon's signed- 


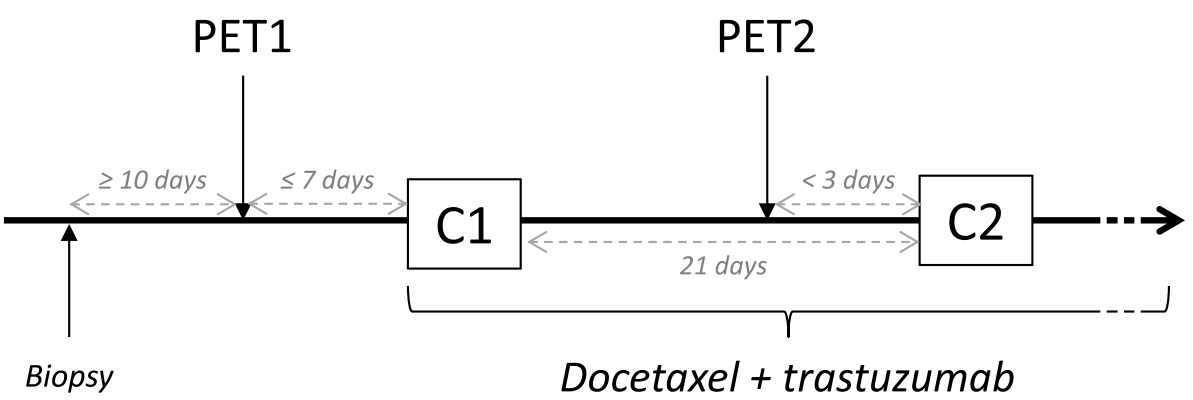

Fig. 1 Study design. The first PET scan was realised within 7 days before the first cycle of chemotherapy (C1). The second PET scan was realised less than 3 days before the second cycle of chemotherapy (C2). PET: Positron emission tomography; C1/2: cycle 1/2

rank test or paired Student's t-tests. Confidence intervals were based on hypothesis-testing using these two tests. For comparisons between the groups of relative weight variation, we used ANOVA, Welch's ANOVA or the Kruskal-Wallis' test (with the Tukey-Kramer method, Dunn's test with Holm correction or the Games-Howell test in a post-hoc analysis). A subgroup analysis was also conducted on the relative weight subgroups, without multiple testing corrections. It is worth noting that, for the main objective (before/after difference in SUVmax), with 109 patients it can be thought that our study had enough power $(>85 \%)$ to detect an effect size of 0.3 (paired t-test, $\alpha=0.05)$. Similarly, for the secondary objective of finding a correlation between the weight variation and the SUVmax variation, the power to detect a coefficient equal to 0.3 can be expected to reach $80 \%$.

\section{Results}

\section{Patient characteristics}

The characteristics of the 109 women included in this study are presented in Table 1 . The patients' median age was 48 years. Before chemotherapy, their mean BMI was $25.1 \mathrm{~kg} / \mathrm{m}^{2}$ (SD 5.7), 25.7\% $(n=28)$ of the population were overweight and $13.8 \%(n=15)$ were obese. The majority of the PET scans occurred in warm seasons, with 43.1\% $(n=47)$ PET scans performed in summer, $19.3 \%$ $(n=21)$ in spring and $20.2 \%(n=22)$ in autumn and $17.4 \%(n=19)$ in winter. All patients are maintained euthyroid. Eight patients were under beta-blockers at PET 1 (before chemotherapy) but were not excluded from the analyses because this does not interfere with SUVmax variation after one course of chemotherapy.

\section{Weight variation}

Patient weight did not change between PET 1 and PET 2 because of the short period between these two images. In the overall population, the mean weight change from baseline to the end of neoadjuvant chemotherapy was $1.5 \mathrm{~kg}(95 \% \mathrm{CI}[0.5,2.3], p=0.001)$, or, in relative difference, $1.9 \%$ (95\% CI [0.8, 3.02], $p=0.001): 10.1 \%(n=11)$ of the patients lost more than $5 \%$ of their initial weight
(LOSS subgroup) and $29.4 \%(n=32)$ gained more than $5 \%$ of their initial weight (GAIN subgroup), while $60.6 \%$ $(n=66)$ remained stable.

For the entire period of treatment (from baseline to the last administration of trastuzumab), the mean weight change for the overall population was a gain of $1.2 \mathrm{~kg}$ (95\% CI $[0.29,2], p=0.011)$, or, in relative difference, $2.08 \%$ (95\% CI $[0.56,3.35], p=0.007$ ).

The treatment arm was not linked to weight variation, whether during neoadjuvant treatment $(p=0.147)$ or after the end of the overall period of treatment $(p=$ $0.637)$.

There were significant differences between the GAIN and LOSS patient subgroups (Table 1). At baseline, patients who lost weight were older compared to those who gained weight $(p=0.018)$ and had a higher initial BMI $\left(31.2 \mathrm{~kg} / \mathrm{m}^{2}\right.$ (SD 8.4) against $22.6 \mathrm{~kg} / \mathrm{m}^{2}$ (SD 3.7) for the GAIN patient subgroup) $(p=0.01)$. Finally, there was more axillary node involvement in the GAIN patient subgroup compared to the STABLE and LOSS subgroups $(p=0.029)$.

\section{${ }^{18}$ F-FDG uptake variation after one course of chemotherapy}

Overall, after one course of chemotherapy, ${ }^{18}$ F-FDG uptake in the BAT regions decreased (weak statistical significance) by 0.05 (95\% CI $[-0.1,-0.01], p=0.022)$, or, in relative difference, by $4.7 \%(p=0.056)$.

After one course of chemotherapy, BAT activity decreased for $57 \%(n=62)$ of the patients and increased for $43 \%(n=47)$. No variation in ${ }^{18}$ F-FDG uptake in the muscle and liver control measures was observed. However, in contralateral breast white adipose tissue there was a decrease of weak statistical significance in $\mathrm{SUV}_{\max }$ $(-0.02 ; 95 \%$ CI $[-0.03 ; 0] ; p=0.043)$.

\section{Factor influencing ${ }^{18} \mathrm{~F}$-FDG uptake and the association between weight variation and ${ }^{18} \mathrm{~F}$-FDG uptake}

The mean initial ${ }^{18}$ F-FDG uptake (PET1: before chemotherapy) in the BAT regions was correlated with initial weight but was independent from age, initial BMI and 
Table 1 Patient characteristics according to subgroup of weight variation during chemotherapy. ( $p$ represents the $p$-value based on ANOVA, Welch's ANOVA, or Kruskal-Wallis test for continuous data, and the Chi-squared test for categorical data)

\begin{tabular}{|c|c|c|c|c|c|c|c|c|c|}
\hline \multirow{2}{*}{ Overall } & \multicolumn{2}{|c|}{ Overall } & \multicolumn{2}{|c|}{ GAIN } & \multicolumn{2}{|c|}{ STABLE } & \multicolumn{2}{|c|}{ LOSS } & $p$ \\
\hline & $n$ & & $n$ & & $n$ & & $n$ & & \\
\hline Median age (range) - yrs & 109 & $48(25-74)$ & 32 & $48(26-62)$ & 66 & $49(25-74)$ & 11 & $61(40-70)$ & 0.024 \\
\hline \multicolumn{10}{|l|}{ Mean weight $(S D)-\mathrm{kg}$} \\
\hline At baseline & 109 & $66.5(15.2)$ & 32 & $60.2(8.9)$ & 66 & $67.1(14.8)$ & 11 & $81.5(21.5)$ & 0.01 \\
\hline At the end of chemotherapy & 109 & $67.5(14)$ & 32 & $65.3(9.8)$ & 66 & $67.5(14.6)$ & 11 & $73.8(19.6)$ & 0.686 \\
\hline At the end of Herceptin ${ }^{\circledast}$ & 109 & $67.1(14.5)$ & 32 & $63.9(9.7)$ & 61 & $67.6(15.1)$ & 10 & $73.8(21.3)$ & 0.212 \\
\hline \multicolumn{10}{|l|}{$\mathrm{BMI}(\mathrm{SD})-\mathrm{kg} / \mathrm{m}^{2}$} \\
\hline At baseline & 109 & $25.1(5.7)$ & 32 & $22.6(3.7)$ & 66 & $25.3(5.2)$ & 11 & $31.2(8.4)$ & 0.005 \\
\hline At the end of chemotherapy & 109 & $25.5(5.3)$ & 32 & $24.5(4.1)$ & 66 & $25.5(5.2)$ & 11 & $28.3(7.8)$ & 0.579 \\
\hline At the end of Herceptin ${ }^{\circledast}$ & 109 & $25.3(5.5)$ & 32 & $24.0(4.1)$ & 61 & $25.5(5.4)$ & 10 & $28.5(8.5)$ & 0.148 \\
\hline Contraceptive status — \% & & & & & & & & & 0.203 \\
\hline Yes & 52 & 47.7 & 19 & 59.4 & 30 & 45.5 & 3 & 27.3 & \\
\hline No & 10 & 9.2 & 3 & 9.4 & 6 & 9.1 & 1 & 9.1 & \\
\hline Sterile & 12 & 11 & 4 & 12.5 & 8 & 12.1 & 0 & 0 & \\
\hline Menopaused & 35 & 32.1 & 6 & 18.8 & 22 & 33.3 & 7 & 63.6 & \\
\hline \multicolumn{10}{|l|}{ Tumor - \% } \\
\hline pT & & & & & & & & & 0.078 \\
\hline $\mathrm{T} 2$ & 84 & 77.1 & 23 & 71.9 & 55 & 83.3 & 6 & 54.5 & \\
\hline $\mathrm{T} 3$ & 25 & 22.9 & 9 & 28.1 & 11 & 16.7 & 5 & 45.5 & \\
\hline $\mathrm{pN}$ & & & & & & & & & 0.048 \\
\hline No & 50 & 45.9 & 9 & 28.1 & 36 & 54.5 & 5 & 45.5 & \\
\hline N1 & 59 & 54.1 & 23 & 71.9 & 30 & 45.5 & 6 & 54.5 & \\
\hline M & & & & & & & & & 0.745 \\
\hline MO & 105 & 96.3 & 31 & 96.9 & 63 & 95.5 & 11 & 100 & \\
\hline Mx & 4 & 3.7 & 1 & 3.1 & 3 & 4.5 & 0 & 0 & \\
\hline SBR grade & & & & & & & & & 0.36 \\
\hline 1 & 1 & 0.9 & 1 & 3.1 & 0 & 0 & 0 & 0 & \\
\hline$\|$ & 50 & 45.9 & 11 & 34.4 & 33 & 50 & 6 & 54.5 & \\
\hline III & 56 & 51.4 & 19 & 59.4 & 32 & 48.5 & 5 & 45.5 & \\
\hline Unknown & 2 & 1.8 & 1 & 3.1 & 1 & 1.5 & 0 & 0 & \\
\hline \multicolumn{10}{|l|}{$\mathrm{IHC}$ results } \\
\hline Overexpressed & 106 & 97.2 & 32 & 100 & 63 & 95.5 & 11 & 100 & \\
\hline Non-determined & 3 & 2.8 & 0 & 0 & 3 & 4.5 & 0 & 0 & \\
\hline \multicolumn{10}{|l|}{ Treatment — \% } \\
\hline Docetaxel + Trastuzumab + Bevacizumab & 35 & 32.1 & 7 & 21.9 & 23 & 34.8 & 5 & 45.5 & \\
\hline Docetaxel + Trastuzumab & 74 & 67.9 & 25 & 78.1 & 43 & 65.2 & 6 & 54.5 & \\
\hline
\end{tabular}

season. Although the mean initial $\mathrm{SUV}_{\max }$ (supraclavicular + cervical) was not statistically significantly different between subgroups, the supraclavicular initial $\mathrm{SUV}_{\max }$ was significantly higher in the GAIN subgroup than in the LOSS subgroup (right side: $p=0.006$; left side: $p<0.001)$.
${ }^{18} \mathrm{~F}$-FDG uptake in the BAT regions after one course of chemotherapy was not correlated with BMI $(p=$ $0.078)$, age $(p=0.7)$ or season $(p=0.51)$.

The GAIN patient subgroup underwent a significant decrease in ${ }^{18} \mathrm{~F}$-FDG after one course of treatment, with a 13.4\% reduction (PET1: 1.31 (SD 1) versus PET2: 0.97 
(SD 0.87); $p=0.042$ ) (Table 2). Among the GAIN subgroup patients, $69 \%(n=22)$ had a decrease in BAT activity. Patients who lost weight and those who remained stable had no significant variation in ${ }^{18}$ F-FDG uptake. Overall, there was no significant relationship between SUVmax variation and weight variation $(p=0.181)$.

\section{Discussion}

This study is the first to show the impact of one course of chemotherapy on BAT activity in a large population of breast cancer patients. The patients who gained weight ( $>5 \%$ of initial weight) during neoadjuvant chemotherapy were those who underwent a significant decrease in BAT activity. This study confirms the results of the previous pilot study conducted by our team, suggesting that chemotherapy induces a decrease in BAT activity particularly for patients who undergone weight gain [24]. Among the factors potentially implicated in BAT activity variation that were tested in our analyses (age, initial weight, BMI, season), none was found to be statistically significant. Thus, chemotherapy seems to be the only factor affecting BAT activity.

Weight variation is commonly observed among breast cancer patients in the year following diagnosis [7, 2936]. In the present study, $29.4 \%$ of the patients gained weight and $10.1 \%$ lost weight. This is consistent with previous results. It has been shown that during different types of chemotherapy (using the threshold of 5\%), 25\% of the patients gained weight, $10 \%$ lost weight and $65 \%$ remained stable [37]. In addition, patients treated with chemotherapy involving trastuzumab exhibited greater weight gain than patients treated without trastuzumab. The authors suggested that the reason was the longer duration of regimens including trastuzumab [37]. BAT activity variation could be implicated in weight variation. Gadéa et al. in a study on 26 breast cancer patients showed that patients who gained weight (after 6 courses of neoadjuvant taxane-based chemotherapy) had a significant decrease in BAT activity after the first course of treatment [24].

A recent retrospective study conducted on cancer patients $(n=37)$ compared body fat mass in patients with and without ${ }^{18}$ F-FDG uptake [38]. The authors showed that the presence of BAT activity was associated with a low ratio of abdominal fat to total fat, and alongside less abdominal obesity. According to the literature data, it could be hypothesised that a decrease in BAT activity, associated with later weight gain, could correspond to a gain in abdominal fat mass. It has been shown that hibernoma resection (a benign tumor histologically similar to brown adipose tissue) is associated with an increase in fat mass gain (mainly abdominal) [39]. However, it is well known that the excess of abdominal adipose tissue is a factor for poor prognosis because of its role in different metabolic pathway disturbances (insulin resistance, adipokines, etc.) and oestrogen production.

The present study has some limitations. The specific procedure for the conduct of PET-CT scans is not ideal for the aim of our ancillary study (designed to avoid brown adipose tissue activation). It would have been interesting to assess the evolution of the patients' body composition to understand the fat and lean body mass changes potentially induced by BAT variations. Moreover, the information about hormone receptor status could have been correlated with these body mass changes and prognosis. Currently, the realisation of early PET-scan routinely is not a recommendation and medico-economic studies will be required to assess feasibility. Investigations on the impact of BAT on energy imbalance, and particularly on energy intake, would also be an interesting perspective. Furthermore, the study of long-term survival rates could provide information on the impact of such changes on prognosis.

\section{Conclusion}

To the best of our knowledge, this study is the first in a cohort of this type to evidence that one course of chemotherapy induces a decrease in BAT activity among breast cancer patients. Moreover, the patients gaining weight ( $>5 \%$ of initial weight) were those who underwent the greatest BAT activity decrease compared to those who were stable or who lost weight. Further

Table $2^{18}$ F-FDG intensity (SUVmax) variation after one course of chemotherapy. (on lines 4 and 6, p represents the p-value based on Wilcoxon's signed-rank test or the paired Student's t-test for before/after variation; in the last column, $p$ is the $p$-value based on Welch's ANOVA or Kruskal-Wallis test for the differences across the three groups of weight variation)

\begin{tabular}{|c|c|c|c|c|c|c|}
\hline & & Overall population $(n=109)$ & GAIN $(n=32)$ & STABLE $(n=66)$ & $\operatorname{LOSS}(n=11)$ & $p$ \\
\hline \multicolumn{2}{|c|}{ SUVmax before: mean (SD) } & $1.16(0.88)$ & $1.31(1)$ & $1.14(0.86)$ & $0.86(0.38)$ & 0.201 \\
\hline \multicolumn{2}{|c|}{ SUVmax after: mean (SD) } & $1.02(0.9)$ & $0.97(0.87)$ & $1.08(0.98)$ & $0.8(0.24)$ & 0.537 \\
\hline \multirow[t]{4}{*}{$\Delta S U V \max (\mathrm{SD})$} & $\mathrm{kg}$ & $-0.14(0.85)$ & $-0.34(0.98)$ & $-0.06(0.85)$ & $-0.05(0.23)$ & 0.322 \\
\hline & $p$ & 0.022 & 0.022 & 0.254 & 0.898 & \\
\hline & $\%$ & $-4.38(34.07)$ & $-13.42(35.82)$ & $-0.35(34.45)$ & $-2.27(21.6)$ & 0.28 \\
\hline & $p$ & 0.056 & 0.042 & 0.399 & 0.735 & \\
\hline
\end{tabular}


studies are warranted in order to define the relationship between chemotherapy and BAT activity more precisely. It would also be very interesting to study the evolution of body composition according to BAT activity among breast cancer patients treated with chemotherapy, and its potential impact on survival.

\section{Supplementary information}

Supplementary information accompanies this paper at https://doi.org/10. 1186/s12885-020-6591-3.

Additional file 1: [18F]-fluorodeoxyglucose (FDG) positron emission tomography (PET) procedures (adapted from AVATAXHER trial)

\section{Abbreviations}

${ }^{18}$ F-FDG: Fluorine-18 fluorodeoxyglucose; BAT: Brown adipose tissue; BMI: Body mass index; HER2: Human epidermal growth factor receptor 2; PET-CT: Positron emission tomography-compute tomography; REE: Resting energy expenditure; ROI: Region of interest; SUV $_{\text {max: }}$ Maximum standardized uptake value; UCP1: Uncoupling protein-1

\section{Acknowledgments}

We would like to thank ROCHE for allowing us to use the PET/CT scan data and for providing the clinical data.

\section{Authors' contributions}

$A G, E T, X D$ wrote the original draft of the paper and contributed to acquisition and interpretation of data; $\mathrm{MC}$ and $\mathrm{BB}$ contributed to reviewing the PET-PT scans; BB, EG, CM and BC reviewed and edited the paper. IM performed the formal analyses. All authors read and approved the final version of the manuscript. All authors meet the four main criteria develop by ICMJE.

\section{Funding}

None.

\section{Availability of data and materials}

The data used in this study are available from the AVATAXHER study database. However, data are only available for the authors due to the legislation of data protection.

\section{Ethics approval and consent to participate}

The study was approved by the local ethics committee (Comité de Protection des Personnes Est I, Faculté de Médecine, Dijon; committee's reference number: 2009/46) and the competent authority. The study was performed in accordance with the Declaration of Helsinki.

As this study is a retrospective one, a non-opposition letter has been delivered to the patients in order to inform them about the research and their right to object to the use of their data.

\section{Consent for publication}

Not applicable.

\section{Competing interests}

The authors declare that they have no competing interests.

\section{Author details}

${ }^{1}$ Centre Jean PERRIN, INSERM, U1240 Imagerie Moléculaire et Stratégies Théranostiques, Université Clermont Auvergne, F-63011 Clermont-Ferrand,

France. ${ }^{2}$ Délégation Recherche Clinique \& Innovation, Centre Jean PERRIN, Centre de Lutte contre le Cancer, 58 rue Montalembert, F-63011 Clermont-Ferrand, France. ${ }^{3}$ Centre d'Investigation Clinique, UMR501, F-63001 Clermont-Ferrand, France. ${ }^{4}$ Service de Médecine Nucléaire, Centre Jean PERRIN, Centre de Lutte contre le Cancer, 58 rue Montalembert, F-63000 Clermont-Ferrand, France. ${ }^{5} \mathrm{CH}$ Emile ROUX, 12 Boulevard Docteur, F-43000 le Puy en Velay, France. ${ }^{6}$ Département d'oncologie médicale, Centre Georges-François Leclerc, 1 rue du Professeur Marion, F-21000 Dijon, France.
Received: 16 October 2019 Accepted: 30 January 2020

Published online: 04 February 2020

\section{References}

1. Kroenke $\mathrm{CH}$, Chen WY, Rosner B, Holmes MD. Weight, weight gain, and survival after breast cancer diagnosis. J Clin Oncol. 2005;23(7):1370-8.

2. Caan BJ, Kwan ML, Hartzell G, Castillo A, Slattery ML, Sternfeld B, et al. Prediagnosis body mass index, post-diagnosis weight change, and prognosis among women with early stage breast cancer. Cancer Causes Control. 2008; 19(10):1319-28.

3. Mutschler NS, Scholz C, Friedl TWP, Zwingers T, Fasching PA, Beckmann MW, et al. Prognostic impact of weight change during adjuvant chemotherapy in patients with high-risk early breast cancer: results from the ADEBAR study. Clinical Breast Cancer. 2018;18(2):175-83 1 avr

4. Gadéa É, Thivat É, Wang-Lopez Q, Viala M, Paulon R, Planchat É, et al. Poor prognostic value of weight change during chemotherapy in non-metastatic breast cancer patients: causes, mechanisms involved and preventive strategies. Bull Cancer. 2013;100(9):865-70.

5. Demark-Wahnefried W, Rimer BK, Winer EP. Weight gain in women diagnosed with breast cancer. J Am Diet Assoc. 1997;97(5):519-26 529; quiz 527-8

6. Demark-Wahnefried W, Peterson BL, Winer EP, Marks L, Aziz N, Marcom PK, et al. Changes in weight, body composition, and factors influencing energy balance among premenopausal breast cancer patients receiving adjuvant chemotherapy. J Clin Oncol. 2001;19(9):2381-9 1 mai.

7. Saquib N, Flatt SW, Natarajan L, Thomson CA, Bardwell WA, Caan B, et al. Weight gain and recovery of pre-cancer weight after breast cancer treatments: evidence from the women's healthy eating and living (WHEL) study. Breast Cancer Res Treat. 2007;105(2):177-86.

8. Gadéa E, Thivat E, Planchat E, Morio B, Durando X. Importance of metabolic changes induced by chemotherapy on prognosis of early-stage breast cancer patients: a review of potential mechanisms. Obes Rev. 2012;13(4): 368-80.

9. Demark-Wahnefried W, Hars V, Conaway MR, Havlin K, Rimer BK, McElveen $\mathrm{G}$, et al. Reduced rates of metabolism and decreased physical activity in breast cancer patients receiving adjuvant chemotherapy. Am J Clin Nutr. 1997:65(5):1495-501.

10. Harvie MN, Campbell IT, Baildam A, Howell A. Energy balance in early breast cancer patients receiving adjuvant chemotherapy. Breast Cancer Res Treat. 2004;83(3):201-10.

11. Bargut TCL, Aguila MB, Mandarim-de-Lacerda CA. Brown adipose tissue: updates in cellular and molecular biology. Tissue Cell. 2016;48(5):452-60.

12. Richard D, Picard F. Brown fat biology and thermogenesis. Front Biosci (Landmark Ed). 2011;16:1233-60.

13. Lowell BB, S-Susulic V, Hamann A, Lawitts JA, Himms-Hagen J, Boyer BB, et al. Development of obesity in transgenic mice after genetic ablation of brown adipose tissue. Nature. 1993;366(6457):740-2.

14. Feldmann HM, Golozoubova V, Cannon B, Nedergaard J. UCP1 ablation induces obesity and abolishes diet-induced thermogenesis in mice exempt from thermal stress by living at thermoneutrality. Cell Metab. 2009:9(2):2039.

15. Ong FJ, Ahmed BA, Oreskovich SM, Blondin DP, Haq T, Konyer NB, et al. Recent advances in the detection of brown adipose tissue in adult humans: a review. Clin Sci. 2018;132(10):1039-54.

16. Nedergaard J, Bengtsson T, Cannon B. Three years with adult human brown adipose tissue. Ann N Y Acad Sci. 2010;1212:E20-36.

17. Cypess AM, Lehman S, Williams G, Tal I, Rodman D, Goldfine AB, et al. Identification and importance of brown adipose tissue in adult humans. $\mathrm{N}$ Engl J Med. 2009;360(15):1509-17.

18. Virtanen KA, Lidell ME, Orava J, Heglind M, Westergren R, Niemi T, et al. Functional brown adipose tissue in healthy adults. N Engl J Med. 2009; 360(15):1518-25

19. Cook GJ, Fogelman I, Maisey MN. Normal physiological and benign pathological variants of 18-fluoro-2-deoxyglucose positron-emission tomography scanning: potential for error in interpretation. Semin Nucl Med. 1996;26(4):308-14.

20. Cohade C, Osman M, Pannu HK, Wahl RL. Uptake in supraclavicular area fat (« USA-Fat »): description on 18F-FDG PET/CT. J Nucl Med. 2003;44(2):170-6.

21. Rohren EM, Turkington TG, Coleman RE. Clinical applications of PET in oncology. Radiology. 2004;231(2):305-32. 
22. Nedergaard J, Bengtsson T, Cannon B. Unexpected evidence for active brown adipose tissue in adult humans. Am J Physiol Endocrinol Metab. 2007;293(2):E444-52.

23. Engel H, Steinert H, Buck A, Berthold T, Huch Böni RA, von Schulthess GK. Whole-body PET: physiological and artifactual fluorodeoxyglucose accumulations. J Nucl Med. 1996;37(3):441-6.

24. Gadea E, Thivat E, Merlin C, Paulon R, Kwiatkowski F, Chadeyras J-B, et al. Brown adipose tissue activity in relation to weight gain during chemotherapy in breast cancer patients: a pilot study. Nutr Cancer. 2014; 66(7):1092-6.

25. Rousseau C, Bourbouloux E, Campion L, Fleury N, Bridji B, Chatal JF, et al. Brown fat in breast cancer patients: analysis of serial (18) F-FDG PET/CT scans. Eur J Nucl Med Mol Imaging. 2006;33(7):785-91.

26. Coudert B, Pierga J-Y, Mouret-Reynier M-A, Kerrou K, Ferrero J-M, Petit T, et al. Use of [(18) F]-FDG PET to predict response to neoadjuvant trastuzumab and docetaxel in patients with HER2-positive breast cancer, and addition of bevacizumab to neoadjuvant trastuzumab and docetaxel in [(18) F]-FDG PET-predicted non-responders (AVATAXHER): an open-label, randomised phase 2 trial. Lancet Oncol. 2014;15(13):1493-502.

27. Bahler L, Holleman F, Booij J, Hoekstra JB, Verberne HJ. Interobserver and intraobserver variability for the assessment of brown adipose tissue activity on 18F-FDG PET-CT. Nucl Med Commun. 2016:37(4):363-71.

28. Hany TF, Gharehpapagh E, Kamel EM, Buck A, Himms-Hagen J, von Schulthess GK. Brown adipose tissue: a factor to consider in symmetrical tracer uptake in the neck and upper chest region. Eur J Nucl Med Mol Imaging. 2002;29(10):1393-8.

29. Goodwin PJ, Ennis M, Pritchard KI, McCready D, Koo J, Sidlofsky S, et al. Adjuvant treatment and onset of menopause predict weight gain after breast cancer diagnosis. J Clin Oncol. 1999;17(1):120-9.

30. Thivat E, Thérondel S, Lapirot O, Abrial C, Gimbergues P, Gadéa E, et al. Weight change during chemotherapy changes the prognosis in non metastatic breast cancer for the worse. BMC Cancer. 2010;10:648.

31. Makari-Judson G, Judson CH, Mertens WC. Longitudinal patterns of weight gain after breast cancer diagnosis: observations beyond the first year. Breast J. 2007:13(3):258-65.

32. Gadéa E, Thivat E, Dubray-Longeras P, Arbre M, Van-Praagh I, MouretReynier M-A, et al. Prospective study on body composition, energy balance and biological factors changes in post-menopausal women with breast cancer receiving adjuvant chemotherapy including taxanes. Nutr Cancer. 2018;70(7):1-10

33. Heideman WH, Russell NS, Gundy C, Rookus MA, Voskuil DW. The frequency, magnitude and timing of post-diagnosis body weight gain in Dutch breast cancer survivors. Eur J Cancer. 2009;45(1):119-26.

34. Irwin ML, McTiernan A, Baumgartner RN, Baumgartner KB, Bernstein L, Gilliland FD, et al. Changes in body fat and weight after a breast cancer diagnosis: influence of demographic, prognostic, and lifestyle factors. J Clin Oncol. 2005;23(4):774-82.

35. Rock CL, Flatt SW, Newman V, Caan BJ, Haan MN, Stefanick ML, et al. Factors associated with weight gain in women after diagnosis of breast cancer. Women's healthy eating and living study group. J Am Diet Assoc. 1999; 99(10):1212-21.

36. Trédan O, Bajard A, Meunier A, Roux P, Fiorletta I, Gargi T, et al. Body weight change in women receiving adjuvant chemotherapy for breast cancer: a French prospective study. Clin Nutr. 2010;29(2):187-91.

37. Winkels RM, Beijer $S$, van Lieshout R, van Barneveld D, Hofstede J, Kuiper J, et al. Changes in body weight during various types of chemotherapy in breast cancer patients. e-SPEN J. 2014;9(1):e39-44.

38. Green AL, Bagci U, Hussein S, Kelly PV, Muzaffar R, Neuschwander-Tetri BA, et al. Brown adipose tissue detected by PET/CT imaging is associated with less central obesity. Nucl Med Commun. 2017;38(7):629-35.

39. Gadea E, Thivat E, Paulon R, Mishellany F, Gimbergues P, Capel F, et al. Hibernoma: a clinical model for exploring the role of brown adipose tissue in the regulation of body weight? J Clin Endocrinol Metab. 2014;99(1):1-6.

\section{Publisher's Note}

Springer Nature remains neutral with regard to jurisdictional claims in published maps and institutional affiliations.

Ready to submit your research? Choose BMC and benefit from:

- fast, convenient online submission

- thorough peer review by experienced researchers in your field

- rapid publication on acceptance

- support for research data, including large and complex data types

- gold Open Access which fosters wider collaboration and increased citations

- maximum visibility for your research: over $100 \mathrm{M}$ website views per year

At BMC, research is always in progress.

Learn more biomedcentral.com/submissions 